\title{
TYPOLOGY OF THE URBAN FABRIC: TRANSPORT SYSTEM, AS A CITY DEVELOPMENT FORCE
}

Eva Lovra ${ }^{1}$

УДК: $656.1: 711.4$

DOI:10.14415/konferencijaGFS 2015.089

Rezime: Studija je zasnovana na pretpostavci, da je urbano tkivo modernog grada evoluirao na teritoriji nekadašnjeg kraljevstva iz dualističkog perioda, između 1867. $i$ 1918. godine. Tokom sadašnjeg istraživanja primarni cilj nam je ispitivanje osnovnog sistema gradskog tkiva, zbog uspešnog predstavljanja $i$ definisanja sistema procenjivanja estetike nasleđa. Metodologija vodi kroz tipologiju strukturnih promena gradskog tkiva (ulične linije, sistemi trgova, morfologije kao nasleđe promena modaliteta prevoza). Osećaj savremenosti zavisi od strukturalne i morfološke informacije o urbanom tkivu. Tipologijska istraživanja urbanog tkiva u gradotvornom smislu bavi sa fenomenom promene transporta, čije dostignuće može da bude $i$ savremeni oblik određenog dela grada.

Ključne reči: tipologija, savremeni oblik grada, modalitet prevoza, dualizam

\section{UVOD}

Urbanizacija ispitivanog razdoblja, između 1867. i 1918., to jest Dualizma ${ }^{2}$, počela se razvijati usled ekonomskog restrukturisanja. Urbanizacija je bila najintenzivnija od 1890. godine na teritoriji Mađarske Kraljevine. U Mađarskoj članovi XLII zakona iz 1870. godine i članovi XVIII zakona iz 1871. godine su uredili zakonitost urbane zajednice [1]. U popisima iz 1869. godine već su zamenjene kategorije slobodnog kraljevskog i stepskog grada sa organizovanim kategorijama opštinskog grada i gradova organizovanog odbora, čiji status nije bio jednak sa prethodnima. Sam proces utice na karakteristike tadasnjih gradova, a njegova priroda je modernizacija grada, koja je imala različite urbano-razvojne snage. Ubrzano su se razvijali gradovi koji su bili železnički centri i na granicama različitih geoekonomskih i pejzažnih područja. Mađarski gradovi su se fokusirali na izgradnju moderne infrastrukture (kanalizacija, voda, struja, plin i telefonske linije), čime se razvijalo i oblik modernog grada, međutim, teritorijalno postojale su značajne razlike u razvoju urbanih jedinica.

\footnotetext{
${ }^{1}$ Ing. Eva Lovra, M.Sc, Ph.D student, University of Pécs, Pollack Mihály Faculty of Engineering and IT, Boszorkány street 2. 7624 Pécs, Hungary, e - mail: lovra.eva@gmail.com

${ }^{2}$ Dualizam je naziv za dvojnu strukturu Austrougarske Monarhije, koja je prema nagodbi iz 1867, sastojala od dve države (Austrijske carevine i Mađarske kraljevine) do 1918.
} 
International conference

Contemporary achievements in civil engineering 24. April 2015. Subotica, SERBIA

\section{METODOLOGIJA}

Morfologija grada i gradskog tkiva može se definisati proučavanjem razvoja urbanog područja, određuje se preko manifestacije forme, njenog postupnog razvoja i interakcija između komponenata urbanog tkiva (ulica, trgova i zelenih površina, javnih površina). Baza morfologije može se opisati preko društvene regulacije, ali uglavnom sa tehničkim šemama i formama, čija tipizacija je evidentna. Teorijski aspekti morfologije su dati preko komponenata prostornih/geografskih obeležja grada, istorije i arhitekture. Morfologija, kao nauka, analizira tipične karaktere urbanih prostornih struktura i procesa razvoja, i izučava fizički karakter na različitim nivoima urbanog tkiva. Nakon analiziranja metoda italijanskih i engleskih urbano-morfoloških škola, istraživanja su razvila metodu koja uzima u obzir mapu grada i korišćenje zemljišta (Conzen- engleska škola) i koristi jednu novu teoriju italijanske morfološke škole koja koristi karte sa dva aspekta, kao otiske kulture i istorije, i u pogledu rekonstrukcije svojih elemenata. Ispitivanje u gradovima Mađarske, tj. tipološka analiza bazira se na metodoliji Konzena (Conzen). Tipologija je osnova specifičnih kompozicija, koja istražuje veze (na nivou ulica, blokova, kuća, zgrada, zelenih površina) između unutrašnje jedinice, strukture i prostora.

\section{FAKTORI MODERNIZACIJE}

Razvojom Budimpešte se, u skladu sa evropskom standardima, bavila država, ali razvoj naselja manjih mađarskih gradova spadao je u nadležnost lokalne uprave i inženjerskih biroa. Kao rezultat intenzivnije urbanizacije stvorena su manja urbana naselja pored gradskog centra, ali za razliku od Pešte bez uništavanja postojeće urbane strukture [2]. Tokom dualističkog perioda izrađen je samo mali broj regulacionih planova koji obuhvataju grad u celosti. Grad Segedin je bio uništen u polavi Tise 1879. godine, zbog čega je cilju obnavljanja grada Lajoš Lehner (Lechner Lajos) napravio urbani plan za rekonstrukciju grada. Najveća inovacija plana je stvaranje modernog modalnog sistema radijalnih puteva i ringova. Tokom 1897. godine Mađarska Udruženja Inženjera i Arhitekata bavila su se konceptom urbane regulacije naselja Miškolca. Plan je razvijen od strane Bele Lipaija (Lippay Béla) železničkog inženjera i glavnog inženjera Karolja Adlera (Adler Károly), s kojim se ne menja struktura grada do te mere kao u Segedinu, ali je u oba slučaja plan bio efekat prethodnih poplava. Plan razvoja grada Šoprona iz 1904. godine vezano je za ime Jožefa Veldera (Wälder József). U gradu su demolirali sistem nekadašnjeg odbrambenog zida i izgradili su sistem bulevara na trasama istih, ali odnos između centra i novih delova grada, koji su bili razdvojeni zbog bulevara ostali su nerešeni [3]. U drugu grupu gradova spadaju ona mesta u kojima se urbani razvoj desio bez svesnog postavljanja principa urbanističkih planova. Sombathelj je želeo da prati primer Beča i Budimpešte. U slučaju Sombathelja gradonačelnici su odigrali veliku ulogu u modernom urbanom razvoju kao i kod Kečkemeta (Elek Kada (Kada Elek) [4]), Targu Mureša (Đerđ Bernady (Bernády György), Temišvara (Karolj Telbis (Telbisz Károly), Đera (Karolj Zechmeister (Zechmeister Károly) i Budimpešte (Ištvan Barczi (Bárczy István) [5]. U nekim gradovima osnovana su udruženja za ulepšavanje grada

\section{2}


Међународна конференција

Савремена достигнућа у грађевинарству 24. април 2015. Суботица, СРБИЈА

1910., koje su se prvenstveno bavile uređenjem zelenila, kao što je slučaj i u Sekešfehervaru, gradu predmeta ovih studija [6].

Modalitet transporta je dominantan deo modernog razvoja grada. Izmedju urbanog razvoja i razvoja saobraćaja postoji uzajamni odnos, što važi i za ispitivane gradove, ali u nekim slučajevima izgradnja pruga nije igrala razvojnu ulogu u urbanizaciji, nego se javlja kao sila degradacije, kao u slučaju Sekešfehervara. Modernizacija transporta u dualističkom periodu se događala paralelno u tri oblasti. Sekešfehervar, počevši od 1897-e godine bavio se teoretskom izgradnjom gradske železnice, koja bi povezala vikend naselje (vinograde) i železničku stanicu. Samo su donešeni teoretski planovi za javni prevoz koji odgovara razvoju moderne urbanizacije grada, 1916-e godine takođe su se bavili planovima gradske železnice, ali te ideje nisu bile uspešne [7].

\section{SEKEŠFEHERVAR KAO POZITIVAN I NEGATIVAN PRIMER}

Dualistički period je značajno unapredio priključivanje Mađarske Zapadnoj Evropi, ali procesi moderne urbanizacije su se desili sa velikim zakašnjenjem, i uticali su na naselja sa dvostrukom diferencijacijom. Razvoj transportnog centra u komercijalnom smislu ni 1870-e godine nije bio uspešan u Sekešfehervaru: akumulacija finansijskih sredstava je bila spora, a blizina Budimpešte, to jest saobraćajno-geografski položaj grada, odnosno sa druge strane, industrijalizacija u odnosu na druge gradove, bila je ispod prosečnog nivoa. Nakon otvaranja železnice, 1860. godine grad se razvija i karakteriše se povećanjem rasta stanovništva, a 1870-ih godina grad postaje važan saobraćajni centar. Razvoj železničkog saobraćaja, sa jedne strane bio je razvojna snaga (razvijali su novi delovi grada), a sa druge strane je uticao na smanjenje razvoja grada (komercijalna i laka industrija u gradu (npr. kožna industrija, mlinovi) je izgubila značajnu ekonomsku snagu, što je uticalo na ekonomski razvoj grada). Ispitivanjem suprotnosti važni principi mogu biti otkriveni u smislu tipološke perspektive u urbanom tkivu. Podunavlje, pod imenom "Pannonia inferior" je bila rimska provincija, zbog toga na planu Sekešfehervara i dan danas se mogu videti pravilne konture bivšeg rimskog castruma. Sagledavanjem sistema plana grada, može se pretpostaviti, da su kao rezultat ubrzane urbanizacije delovi grada prerasli kompaktno istorijsko jezgro. Stvoreni su različito oblikovani okruzi, koji su povezani samo saobraćajnim mrežama grada.

Posle 1867-e godine i ekonomske transformacije, ulična mreža grada u pogledu delova grada nije se značajnijne promenila. Međutim, granice teritorijalnih jedinica su se promenile u tom periodu, a promene su se desile između istorijskog centra i Gornjeg grada, u odnosu na Vodeni grad i Jezero grad [8]. Formirana su nova naselja u gradu, neka naselja i okruzi su spojeni, ali ove promene se zbog nedostatka odgovarajućih mapa ne mogu rekonstruisati. Ulični sistem istorijskog centra grada, upoređujući sa predhodnom mapom grada, nije pretrpeo velike izmene u odnosu na srednji vek. Posle analiziranja karata u hronološkom sistemu može se zaključiti, da je najznačajnija razlika u životu grada rušenje odbrambenih zidova, i na taj način je smanjen obim dvorca $\mathrm{i}$ zatvorenost karaktera centra grada. Urbani rast može se videti duž predgrađa, kao rezultat nove parcelacije i teritorijalne ekspanzije. Prema Pravilima regulacije usvojenim 1874. godine, čime je određen sadržaj projektne dokumentacije [9], propisana je veličina parcele u predgrađu, koja je ubuduće trebala da iznosi najmanje $300 \mathrm{~m}^{2}$. Pravci 
International conference

Contemporary achievements in civil engineering 24. April 2015. Subotica, SERBIA

prigradskog širenja su određeni na osnovu hidrološke sredine. Na osnovu drugog vojnog premeravanja, oko 1863. i sa osvrtom na istorijska dokumenta, može se zaključiti da je izgradnja železnice, koja je blokirala komunikaciju između Vodenog grada južnog dela područja ispod dvoraca i ograničila dalje širenje Vodenog grada prema jugu, u celoj dužini završena.

Treće vojno premeravanje iz 1882. godine je napravljeno u srazmeril: 25000 na teritoriji Sekešfehervara, i u odnosu na drugo vojno premeravanje, u smislu razvoja grada, mogu se identifikovati značajne promene: godine 1860. izgradnja nove pruge prema NoviSenj, železničke linije Buda - Sekešfekervar - Rijeka (1861.); 1869. demoliranje Budim (Palatin) kapije. Sekešfehervar razvija se kao centar železničke raskrsnice, saobraćajna karakteristika grada se pokazala i preko profesionalnog raslojavanja gradskog stanovništva. Pomoću statistike i obrade statističkih podataka, očigledno je da je specifičnost Sekešfehervara prisustvo velikog broja železničkih radnika. Od 1890-ih godina obim železničkog pogona se razvija, a samim tim broj zaposlenih se povećava, zbog toga radnici 1902-e godine traže parcele za gradnju na zemljištama preko puta železničke stanice [10]. U strukturi širenja grada odvaja se Bur - kolonija, koja se nalazi u blizini železnice, gde su živeli radnici istog. Sa širenjem grada i putna mreža je modifikovana, ali važne promene su se desile i u istorijskom centru. Na prelasku iz 19. u 20. vek, južno od centra grada pomoću javne izgradnje nastala je ulica Petefija, pa je u južnom delu grada ova promena transformisala strukturu gradskog saobraćaja. U ovom periodu mogu se identifikovati dve faze formiranja i razvoja modernog grada, prva faza je izgradnja železnice (1860), a druga je novogradnja korita Asalvolđeg - jarka (1885), nakon toga su pokrivali korita i izgradili su sekundarni centar naselja železnice. Teritorija železnice neprekidno se transformisala kao rezultat promenjenog značaja železničkog saobraćaja u životu grada.

Bur - kolonija je naselje zatvorenog tipa, koja je izgrađena na teritoriji između pešadijske kasarne i Asalvolđeg jarka na području železnice. Nakon prijema zahteva za izgradnju, pojavila se urbana struktura koja nije bila povezana sa tradicionalnom strukturom Sekešfehervara, forma parcelacije je postala nezavisna od same geohidrološke karakteristike područja. Tipično inženjerski planirano naselje: ulična mreža kolonije je izgrađena u formi matrice, ulice se seku pod pravim uglom. Kolonija funkcioniše kao nezavisno naselje (mala opština). Južnije od železnice su se razvijala druga naselja (Donji grad). U ovom delu grada su već od 1890-e godine bile izdavane građevinske dozvole. Tradicionalni prigradski izgled teritorije zapadno od Balatonskog puta je posledica masovne stambene izgradnje na prelazu 19. i 20. veka.

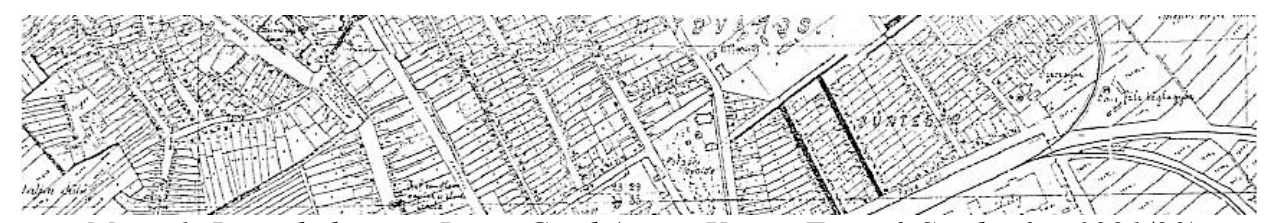

Mapa 1. Bur - kolonija i Donji Grad (mapa Varga-Faragó-Szathmáry 1921/29)

Pored izgradnje prigradskih naselja, na ekspanziju grada i razvoj infrastrukture je uticalo i poboljšanje puteva i uličnih mreža. Najznačajnije infrastrukturalne promene su razvoj uličnih osvetljenja na gas u centru grada, delimično pokrivanje otvorenog sistema

\section{4}


Међународна конференција

Савремена достигнућа у грађевинарству 24. април 2015. Суботица, СРБИЈА

kanalizacije, izgradnja vodovoda i kanalizacije, što je uzrok revitalizacije glavnih puteva i uličnih mreža sredinom 1910-e godine [11].

Urbani razvoj Sekešfehervara je bio neprekidan do Prvog svetskog rata, zahvaljujući železničkom saobraćaju gradili su se novi delovi grada, dok sa druge strane izgradnja železnice i povoljniji uslovi saobraćaja su imali negativan uticaj na trgovinu i industriju grada. Zbog blizine Budimpešte, već u prvoj polovini 19. veka lokalna trgovinska i zanatska klasa je potisnuta masovnom proizvodnjom iz Pešte. Proces je ojačan u negativnom smislu u drugoj polovini veka (lokalna trgovina i zanatstvo su izgubili trku sa potencijalima masovne proizvodnje u Budimpešti). Kao pozitivan efekat možemo smatrati povišen broj izlagača na godišnjim sajmovima [12].

\section{ZAKLJUČAK}
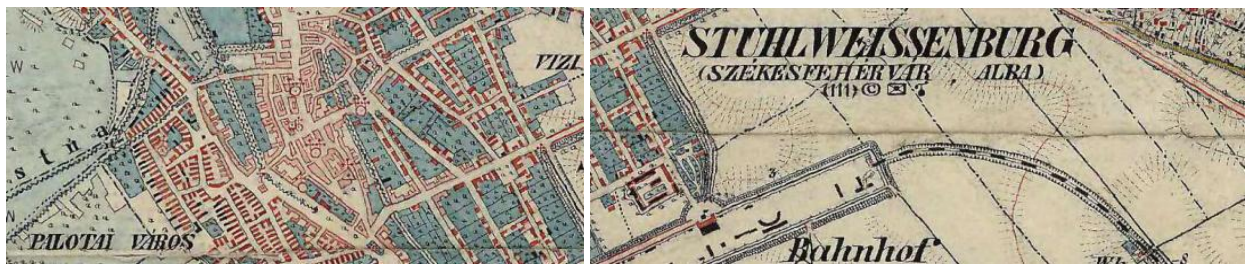

Mapa 2a. Linije castruma. Mapa $2 b$.

Teritorija Bur - kolonije (Arcanium Adatbázis Kft.)

Definisanje tipološkog sistema gradskog tkiva Sekešfehervara nije jednostavno, komplikuje je činjenica da analizirane mape ne pružaju odgovarajuće informacije o razvojnim smerovima grada. Pomoću dokumenata iz predhodnih istraživanja $i$ ispitane mape može se odrediti baza tipoloških odnosa. Centar grada je okružen odbrambenim zidinama, u istorijskom centru dominira slika baroknog grada. Grad je, kao drugi podunavski gradovi (npr. Pečuj), sačuvao svoju srednjovekovnu uličnu strukturu, koja je povezana sa predgrađima preko kapije dvorca. Dvorac je izgubio zatvoreni karakter $u$ prvoj trećini 19. veka, kada su izgrađene nove ulice, i pokušali su da priključe pregrađe $u$ krvni tok centra grada. Na širenje predgrađa su uticali hidrološki uslovi, tako formirajući strukturu Vodenog grada, ali je planirana urbana struktura ipak izgrađena pored železnice, Bur - kolonija. Kod tog naselja geografski i hidrološki uslovi nisu uzeti u obzir tokom izgradnje. Tradicionalna, istorijska struktura grada je poput radijalnog sistema, koji nije potvrđen ringom. Karakteristično je da, iako su otvorili istorijski centar grada, zbog nedovršnog prelaska između unutrašnjih i spoljašnjih delova (centar periferija), nisu se razvijale ulice na određene linijama. Neodređena putna mreža je delimično rekonstuisana, sistematizovana je pod uticajem železnice, pa je počelo regulisanje prigradskih područja u urbanom duhu. Železnica je, kao snaga urbanizacije, značajna. Postojeća putna mreža je proširena i definisana sa regulisanjem puta koji vodi prema stanici i omogućava otvaranje novih ulica. Struktura grada je proširena i transformisana zbog novih naselja, koja su izgrađena pored železnice. Prema studiji lokalne istorije grada na nivou naselja, i prema analizi razvojnih principa na mapama drugih naselja, na osnovu Konzenove (Conzen) teorije, možemo identifikovati 
karakteristike Sekešfehervara, koje su značajne u slučaju tipologije: vidi se originalni raspored rimskog castruma na osnovi grada; deo unutrašnjeg grada se razvija u radijalnom pravcu, urbana tkiva su zadržala originalni izgled srednjevjekovnog karaktera; istorijski centar je zadržao nekadašnju strukturu uličnih mreža i neodređenost unutar parcele, razvoj novih puteva i izgradnja novih parcelaje planirano i određeno; nove regulisane parcele su formirane van gradskog jezgra čija struktura nije u skladu sa pejzažnim karakteristikama; centralni deo grada je koncentrisan u centralnom prostoru (trgu), između puteva su formirani nepravilni blokovi uskog centra, gde su koncentrisane sekularne i verske institucije; rušenje dela dvorca smanjio je zatvorenost istorijskog centra grad, ali komunikacija između grada i predgrađa je slaba; restrukturisanja snaga urbanog gradskog javnog prevoza nije postignuto zbog nedostatka gradske železnice; kao rezultat železničkog sistema realizovana je planirana urbanizacija - javlja se pozitivan uticaj železničkog saobraćaja (novo naselje), međutim trgovina, koja je tradicionalno bila najveća ekonomska snaga, izgubila je prednost zbog železnice i blizine kapitala.

\section{LITERATURA}

[1] Kovács, E. (editor): Magyarország története 1848-1890. vol. II.,Budimpešta, 1979, str. 836-844.

[2] Winkler, G.: Városépítészet a historizmusban. A historizmus müvészete Magyarországon, Budimpešta 1941 (1993). str.40.

[3] Winkler, G., Sopron építészete a 19. században. Budimpešta, 1988. str. 151-152.

[4] Lovra, E., Utcasávok: Az Alföldi mezővárosok településstruktúrájának változásai, Tudástérkép: Vajdasági Magyar Tudóstalálkozó, Novi Sad, 2014. str. 194 - 201.

[5] Sármány-Parsons, I.: Die Rahmenbedingungen für die „Moderne” in den UngarischenProvizstästen um die Jahrhundertwende. Urbanizáció a dualizmus korában. TanulmányokBudapest múltjából. vol. XXVIII. Budimpešta, 1999. str. 136.

[6] Csurgai Horváth, J.: Székesfehérvár városképi alakulása a dualizmus korában. Struktúraés városkép. A polgári társadalom a Dunántúlon a dualizmus korában. Vesprem, 2002. str. 279-302. [8] = [6] = [12]

[7] SGA IV.B.1405. 1902. No. 15533.

[9] SGA IV. B. 1107. 1867. No. 241.;SGAIV. B. 1405. 1873. No. 1428.

[10]SGA IV. B. 1405. 1903. No. 13773.

[11]SGA IV. B. 1402. 1911.; No. 263., 266., 330. SGA IV. B. 1402. 1912. No. 262.

\section{6}


Међународна конференција

Савремена достигнућа у грађевинарству 24. април 2015. Суботица, СРБИЈА

\title{
TRANSPORT SYSTEM, AS A CITY DEVELOPMENT FORCE, RAILWAY TYPE URBAN FABRIC
}

\begin{abstract}
The study is based on the assumption that the urban fabric of the modern city evolved on the territory of the former Kingdom of the Dualism(1867 - 1918). During the current study the main objective is to examine the basical system of the urban fabric, due to the successful introduction of the system of assessing and defining the aesthetic of heritage. The methodology takes through the typology of structural changes in the urban fabric (street lines, squares systems, morphologycal changes as well as changes in the modes of transport). The sense of modernity depends on the structural and morphological information about the urban fabric. Typological research of the cityscape in terms of urban fabric, dealing with the phenomenon of changes in the transport, its achievements could establish the modern form of particular parts of the city.
\end{abstract}

Key words: typology, the modern form of the city, transportation, Dualism 